Original Article

\title{
THE AWARENESS IN BIOMEDICAL WASTE MANAGEMENT OF NURSING STAFF AT A TERTIARY CARE HOSPITAL OF MANGALORE, SOUTH INDIA
}

\author{
Rashmi Kundapur ${ }^{1}$, Tanmay Bhat ${ }^{2}$, Sanjeev Badiger ${ }^{3} \&$ Rajesh Ballal ${ }^{4}$ \\ ${ }^{1}$ Associate Professor, ${ }^{3}$ Professor Department of Community Medicine \\ ${ }^{2}$ Assistant Professor Department of M edicine, ${ }^{4}$ Professor, Department of Surgery \\ K.S. Hegde M edical Academy, Nitte University, Mangalore - 575 018, India. \\ Correspondence : \\ Rashmi \\ Associate Professor, Department of Community M edicine, K.S. Hegde M edical Academy, \\ Nitte University, M angalore - 575 018, India. \\ Mobile : +919880496567 E-mail : dr.rashmi.kundapur@gmail.com
}

\begin{abstract}
:
Introduction : In country like India, where there is big and complex health care system, mixed economy, private and Government hospitals working together; while providing services generate waste. It is estimated that the quantity of waste generated from hospitals in our country ranges between 0.5 and $2.0 \mathrm{~kg} / \mathrm{bed} / \mathrm{day}$ and annually about 0.33 million tons of waste are generated in India

Aim and objectives: To study the awareness of nursing staff about the biomedical waste segregation in a tertiary care center

M aterial and methods : A cross-sectional study was conducted among the nurses of Justice K.S. Hegde Hospital, Derlakatte. Total of 123 nurses who were present at the time were the study subjects. The pre-tested semi-structured questionnaire which was validated by face validation method was distributed.

Results : The total of $96.66 \%$ of nurses knew the segregation of biomedical waste was the need of the hour. $90 \%$ of them felt they have adequate know ledge about segregation. $96 \%$ knew the color coding of sharps and human anatomical waste. But $99 \%$ knew the colour coding of blood, blood products and microbiological waste. $67 \%$ knew the colour coding of pharmacological waste and double glove disposal. Only 89.3\% were confident that they followed the correct methods of segregation.
\end{abstract}

Keywords: Biomedical waste, Hospital waste, nursing staff

\section{Introduction :}

The Bio-Medical Waste means any solid, fluid or liquid waste including the containers and any intermediate product, which is generated during the diagnosis treatment or immunization of human beings or animal. It includes human tissues, body fluids, excreta, unused drugs, swabs, disposable syringes and sticky bandages etc. ${ }^{1}$ The doctors, nurses, technicians, sweepers, hospital visitors, patients, rag pickers and their relatives are exposed routinely to Bio-

Access this article online Quick Response Code

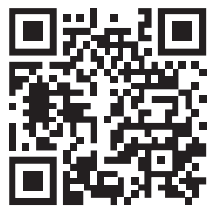

Medical Waste and are at more risk from the many fatal infections due to i n d i s crim i n a t e management. ${ }^{1}$ potential generators of Bio-M edical Waste. $^{2}$
In country like India, where there is big and complex health care system, mixed economy, private and Government hospitals working together; while providing services generate waste. It is estimated that the quantity of waste generated from hospitals in our country ranges between 0.5 and $2.0 \mathrm{~kg} / \mathrm{bed} /$ day and annually about 0.33 million tons of waste are generated in India ${ }^{2}$

Segregation means "separation of different types of wastes by sorting or the systematic separation of Bio-Medical Waste into designated categories." ${ }^{2}$ Hospital waste is not managed properly it proves to be harmful to the environment. It not only poses a threat to the employees working in the hospital, but also to the people surrounding that area. Infectious waste can cause diseases like Hepatitis $A \& B, A I D S$, Typhoid, Boils, etc. If a syringe, previously used by an AIDS patient, is reused, it can affect the person using 
it. So, the hospital staff should dispose of the syringes properly, by cutting the needles of the syringes with the help of a cutter, so that the needle cannot be reused. When waste containing plastics are burnt, Dioxin is produced, which can cause Cancer, birth defects, decreased psychomotor ability, hearing defects, cognitive defects and behavioural alternations in infants.

Y. Saraf, M. Shinde, S.C. Tiwari Study showed that all respondents had good knowledge about segregation of waste material generated in hospital. Although level of knowledge was more among doctors \& nurses as compared to the ward boys $\&$ Sweepers. ${ }^{3}$ Akter $N$, Hussain Z, Trankler J, Parkpian P. It was been quite evident that a satisfactory hospital waste management system in government hospitals and several private clinics was severely lacking. Many doctors and nurses were not fully aware about segregation of waste material generated in hospital. ${ }^{4}$ Rasheed S, Iqbal S, Baig LA, M ufti K. Segregation and use of colour codes revealed gaps, which needed correction. About $70 \%$ of the healthcare facilities used a needle cutter/destroyer for sharps management. ${ }^{5} W$ ith such mixed results we tried to see the awareness about hospital waste segregation among nurses, in a tertiary care hospital.

\section{Material and methods:}

A cross-sectional study was conducted among the nurses of Justice K.S. Hegde Hospital, Derlakatte. Total of 123 nurses who were present at the time were the study subjects. 3 of the questionnaires were not able to be collected, so in the end we had 120 subjects as participants. The pre-tested semi-structured questionnaire which was validated by face validation method was distributed. The anonymity of the participants was maintained and informed verbal consent was taken from the subjects. Also the subjects are given choices of filling the form or leaving it blank. The data was entered $n$ excel and analyzed. The questions contained

\section{Results:}

The total of $96.66 \%$ of nurses knew the segregation of biomedical waste was the need of the hour. $90 \%$ of them felt they have adequate knowledge about segregation. $18 \%$ felt that the knowledge imparted in their course was not adequate enough for their day to day segregation. 20\% of them felt that the ward boys are not competent enough to segregate biomedical waste. When tested for their actual knowledge $96 \%$ knew the color coding of sharps and human anatomical waste. But $99 \%$ knew the colour coding of blood, blood products and microbiological waste. But only $67 \%$ knew the colour coding of pharmacological waste. Similarly when segregation of double gloves which were used in the procedures was asked only $66.6 \%$ answered the correct way. But $80 \%$ had a correct knowledge of hazardous illness due to improper waste management. $10 \%$ of them did not know how to manage the infected Lenin in the hospital. Only $89.3 \%$ were confident that they followed the correct methods of segregation.

Table depicting the awareness of the nursing staff

\begin{tabular}{|c|c|c|}
\hline Factors & Percentage positive & Percentage negative \\
\hline Felt need of segregation among nursing staff & $9.66 \%$ & $3.33 \%$ \\
\hline Self reporting of adequacy in knowledge & $90 \%$ & 7\% (no) and 3\% (don't know) \\
\hline Self reporting of adequacy in training during their college & $82 \%$ & $18 \%$ \\
\hline \multirow[t]{2}{*}{ Nurses perception about ward boys knowledge } & $80 \%$ felt they have & $20 \%$ felt their knowledge \\
\hline & adequate knowledge & is not adequate \\
\hline Knowledge of segregation of sharps and needles & $96 \%$ & $4 \%$ \\
\hline Knowledge of human anatomical waste segregation & $96 \%$ & $4 \%$ \\
\hline Segregation of microbiological and blood products & $99 \%$ & $1 \%$ \\
\hline Knowledge in double glove procedure to segregate the waste & $66 \%$ & $33 \%$ \\
\hline Disinfection of infected lennin & $90 \%$ & $10 \%$ \\
\hline Observation of correct procedure followed by the nurses & $89.3 \%$ & $10.7 \%$ \\
\hline
\end{tabular}




\section{Discussion :}

It is very interesting to know that $90 \%$ of the nursing staff knew about colour coding in biomedical waste which is much higher as compared to earlier studies in north Indiawhich the awareness was much less from $87 \%{ }^{(6)}$ But $97 \%$ of them felt that the knowledge is felt need of the hour. We have seen in all earlier studies ${ }^{(6,7, \text { and } 8)}$ that the sharps color coding and right disposal was a problem in $15-$ $20 \%$. But this problem is only $4 \%$ which is significantly higher knowledge. 99\% knew about blood and blood products which is very good but it was similar in earlier study that this segregation was priority and was higher than $90 \%$. Pharmacological waste and its disposal was always a problem and the knowledge remained poor as in earlier studies ${ }^{(6,7)}$ and also in our study that right disposal is unknown by $23 \%$ of the nurses in our study hospital too. The disposal of double gloves was unknown by $24 \%$ which is a huge gap emphasizing on improvement of their knowledge in biomedical waste management. Though 99\% were aware how the disposal of blood and blood products it is more interesting to know that only $89 \%$ were confident

\section{References:}

1. Mukesh Yadav, Hospital waste - a major problem; Indian journal of Community M edicine;Vol. 8 No. 4, October - December 2001,277

2. The Bio M edical Waste (M anagement and Handling) Rules, 1998.

3. Y. Saraf, M. Shinde, S.C. Tiwari Study of Awareness Status about Hospital Waste management among Personnel and Quantification Indian Journal of Community M edicine Vol. 31, No. 2 (2006-04 - 200606)

4. Akter N, Hussain Z, Trankler J, Parkpian P. Hospital waste management and it's probable health effect: a lesson learned from Bangladesh;Indian J Environ Health. 2002 Apr;44(2):124-37

5. Rasheed S, Iqbal S, Baig LA, M ufti K. Hospital waste management in the teaching hospitals of Karachi;] Pak M ed Assoc. 2005 M ay;55(5):192-5.

6. Jugal Kishore, Ravindra Agarwal, Charu Kohli, Pramod Kumar Sharma, NVKamat, SC Tyagi. Status of Biomedical Waste Management in Nursing Homes of Delhi; India Journal of Clinical and Diagnostic Research. $2014 \mathrm{M}$ ar, Vol-8(3): 56-58

7. N. B. Pandit, H. K. M ehta, G. P. Kartha, S. K. Choudhary. Management of Bio-medical Waste: Awareness and Practices in a District of Gujarat; Indian Journal of Public Health, Vol.XXXXIX No.4 October-December, 2005

8. Rajiv Kumar1, Anil Kumar Gupta1, Arun Kumar Aggarwal and Ashok Kumar. A descriptive study on evaluation of bio-medical waste management in a tertiary care public hospital of North India; Journal of Environmental Health Science \& Engineering 2014, 12:69 on their knowledge of biomedical waste management which is similar to earlier studies ${ }^{(5,6,7,8)}$. Also the commonest problem of infected lenin handling was not known by $10 \%$ that is 12 nurses, which is really big issue needs an immediate training. The biomedical waste is a hazardous material to health which needs more emphasis. We need to follow the continued education for nursing and staff, by addressing this issue repeatedly in their meetings and in their curicullum. It is also found $97 \%$ feel they need such education and $18 \%$ were not happy with the amount of knowledge imparted to them in their courses and feel they need more focus on this matter while they work in hospitals.

\section{Conclusion :}

Though the knowledge of nursing staff is increased in recent years there is a large knowledge gap in certain issues which needs to be addressed.

\section{Acknowledgements:}

All nursing staff of Justice charitable hospital 